\title{
A Gaussia Luciferase Cell-Based System to Assess the Infection of Cell Culture- and Serum-Derived Hepatitis C Virus
}

\section{George Koutsoudakis*, Sofía Pérez-del-Pulgar, Patricia González, Gonzalo Crespo, Miquel Navasa, Xavier Forns}

Liver Unit, Institut D'Investigacions Biomèdics August Pi i Sunyer, Centro de Investigación Biomédica en Red: Enfermedades Hepáticas y Digestivas, Hospital Clínic, Barcelona, Spain

\begin{abstract}
Robust replication of hepatitis C virus (HCV) in cell culture occurs only with the JFH-1 (genotype 2a) recombinant genome. The aim of this study was to develop a system for HCV infection quantification analysis and apply it for the selection of patient sera that may contain cell culture infectious viruses, particularly of the most clinically important genotype 1. Initially, a hepatoma cell line (designated Huh-7.5/EG(4A/4B)GLuc) was generated that stably expressed the enhanced green fluorescent protein (EGFP) fused in-frame to the secreted Gaussia luciferase via a recognition sequence of the viral NS3/4A protease. Upon HCV infection, NS3/4A cleaved at its signal and the Gaussia was secreted to the culture medium, thus facilitating the infection quantification. The Huh-7.5/EG(4A/4B)GLuc cell line provided a rapid and highly sensitive quantification of HCV infection in cell culture using JFH-1-derived viruses. Furthermore, the Huh-7.5/EG(4A/4B)GLuc cells were also shown to be a suitable host for the discovery of anti-HCV inhibitors by using known compounds that target distinct stages of the HCV life cycle; the Z-factor of this assay ranged from 0.72 to 0.75 . Additionally, eighty-six sera derived from HCV genotype $1 \mathrm{~b}$ infected liver transplant recipients were screened for their in vitro infection and replication potential. Approximately $12 \%$ of the sera contained in vitro replication-competent viruses, as deduced by the Gaussia signal, real time quantitative PCR, immunofluorescence and capsid protein secretion. We conclude that the Huh-7.5/EG(4A/4B)GLuc cell line is an excellent system not only for the screening of in vitro replication-competent serum-derived viruses, but also for the subsequent cloning of recombinant isolates. Additionally, it can be utilized for high-throughput screening of antiviral compounds.
\end{abstract}

Citation: Koutsoudakis G, Pérez-del-Pulgar S, González P, Crespo G, Navasa M, et al. (2012) A Gaussia Luciferase Cell-Based System to Assess the Infection of Cell Culture- and Serum-Derived Hepatitis C Virus. PLoS ONE 7(12): e53254. doi:10.1371/journal.pone.0053254

Editor: Birke Bartosch, Inserm, U1052, UMR 5286, France

Received July 3, 2012; Accepted November 27, 2012; Published December 31, 2012

Copyright: (c) 2012 Koutsoudakis et al. This is an open-access article distributed under the terms of the Creative Commons Attribution License, which permits unrestricted use, distribution, and reproduction in any medium, provided the original author and source are credited.

Funding: X. Forns received a grant from Instituto de Salud Carlos III, Ministerio de Economía y Competitividad (PI11/01907), co-funded by Fondo Europeo de Desarrollo Regional (FEDER), Unión Europea, Una manera de hacer Europa; and from the Roche Organ Transplantation Research Foundation (ROTRF, CI: 442035057). The funders had no role in study design, data collection and analysis, decision to publish, or preparation of the manuscript.

Competing Interests: The authors have declared that no competing interests exist.

*E-mail: gkoutsou@clinic.ub.es

\section{Introduction}

Hepatitis $\mathrm{C}$ virus (HCV), which infects $2-3 \%$ of the world's population, is a major cause of chronic hepatitis, leading to liver cirrhosis and hepatocellular carcinoma in a significant portion of infected patients [1]. HCV is an enveloped positive-strand RNA virus that belongs to the Flaviviridae family [2]. The genome of $\mathrm{HCV}$ is composed of the $5^{\prime}$ non-translating region (5' NTR), a single open reading frame encoding at least 10 proteins and the 3' NTR. The viral particle is composed of structural proteins, core (C), and the envelope glycoproteins (E1 and E2). The other nonstructural proteins (NS proteins) include the viroporin ion channel p7, the NS2-3 protease, the NS3 dual-function protein (serine protease and helicase), the NS4A polypeptide, the NS5A phosphoprotein and the NS5B RNA-dependent RNA polymerase (RdRp) [3]. There are six distinct HCV genotypes and multiple subtypes [4]; among these genotypes there exist clusters of global distribution, with types $1 \mathrm{a}$ and $1 \mathrm{~b}$ being the most common, accounting for about $60 \%$ of global infections [5].
In vitro $\mathrm{HCV}$ studies advanced through two breakthroughs: first, subgenomic replicons of subtypes $1 \mathrm{~b}[6,7]$ and la [8], which replicate autonomously and preferably in selected subclones of the human hepatoma cell line Huh-7, proved to be highly permissive for HCV replication; e.g., Huh-7.5 [9] or Lunet cells [10]; second, the JFH-1 (genotype 2a) isolate, which supports a full infectious cycle in cell culture [11], as well as in its intra- and inter-genotypic chimeric derivatives (e.g., the JC1 chimera) [12,13,14]. Although propagation of $\mathrm{HCV}$ in cell culture has been an important contribution to the field, it is generally recognized that while subgenomic replicons do exist for a limited number of strains, only the JFH-1 isolate completes the HCV life cycle in vitro. Hence, the development of new in vitro replication-competent isolates became a priority.

Methodologies and detection methods for $\mathrm{HCV}$ in vitro infection have ranged from immunostaining and quantitative PCR to the use of infectious viruses carrying reporter genes (e.g., Firefly luciferase or Green Fluorescent Protein [GFP]) [15,16]. Overall, cell-based assays which depend on viral enzymes appear 
advantageous to those assays that are based on bulk populations in terms of offering a mean for differentiating between viral and cellular functions. Lee et al. [17] developed a cell-based assay for monitoring HCV NS3/4A protease activity in mammalian cells. Their study described a substrate vector in which the enhanced GFP (EGFP) was fused to the secreted alkaline phosphatise (SEAP) through the NS3/4A protease decapeptide recognition sequence, which spans the NS4A and NS4B junction region (Delta4AB). Mammalian cells stably expressing the EGFP-Delta4AB-SEAP cassette enabled the monitoring of NS3/4A activity upon expression in trans of the protease by subgenomic HCV replicon transfection. Iro et al. [18], created a Huh7 cell line (designated Huh7-J20) expressing the identical cassette for rapid and sensitive quantification of HCV infection in cell culture by JFH-1 or JFH-1 chimeric viruses. Finally, Pan et al et al. [19], generated a similar stable cell line (designated Huh7.5-EG( $\Delta 4 \mathrm{~B} 5 \mathrm{~A}) \mathrm{SEAP}$ ), which is based on the Huh-7.5 cells and the NS4B-NS5A junction region as a recognition sequence for the viral protease .

Recently, a real-time imaging of HCV infection using a fluorescent cell-based reporter system has been described [20]. In this system a cellular marker of HCV infection was constructed based on a known substrate of the NS3/4A protease, the mitochondrially tethered interferon (IFN)- $\beta$ promoter stimulator protein 1 (IPS-1). Huh-7.5 cells stably express a chimeric protein encompassing the C-terminal region of IPS-1 fused to diverse fluorescence proteins alone (Fluorescence Proteins-IPS) or via a nuclear localization sequence (Fluorescence Proteins-NLS-IPS). Chimeric proteins localization followed a mitochondrial pattern along with the single IPS-1 localization. Upon JFH-1 infection or replication of subgenomic replicons of diverse subtypes, expression of the viral protease lead to the IPS substrate recognition and truncation and subsequent re-localization of the fluorescent proteins in the whole cytoplasm or in the nucleus (for those constructs that contained the NLS). This system allowed the monitoring of HCV infection at a single cell level by live-cell imaging of viral propagation.

The aim of the present study was to develop a robust and highly sensitive system for HCV infection quantification analysis. Given the advantages of the NS3/4A protease systems described above, we established a new cell line, designated Huh-7.5/EG(4A/ 4B)GLuc, which stably expresses the construct described by Lee $e t$. al. modified as follows: EGFP was fused to the robust Gaussia luciferase [21] via a recognition sequence for the NS3/4A protease. The utility of this new system was evaluated not only in terms of virus entry and replication inhibition by means of JFH1 infections and known inhibitors neutralizations, but also for the screening of clinical sera with the capacity to contain in vitro replication-competent isolates.

\section{Materials and Methods}

\section{Ethics Statement}

The Investigation and Ethics Committee of Hospital Clinic Barcelona approved our protocol, including the use of human samples, which conformed to the ethical guidelines of the 1975 Declaration of Helsinki. Written informed consent was obtained from all the patients included in this study.

\section{Cell Culture and Cell Lines}

Huh-7.5 [9] (kindly provided by Prof. Charles Rice, The Rockefeller University, NY, USA), and 293T (HEK293T cells, American Type Culture Collection, Manassas, VA, CRL-1573) cells were grown in Dulbecco's modified Eagle medium (DMEM; Invitrogen, Carlsbad, CA) supplemented with $2 \mathrm{mM} \mathrm{L-glutamine,}$ non-essential amino acids, $100 \mathrm{U}$ of penicillin per $\mathrm{ml}, 100 \mu \mathrm{g}$ of streptomycin per $\mathrm{ml}$, and $10 \%$ fetal calf serum (FCS), designated DMEM complete, in an incubator with $5 \% \mathrm{CO}_{2}$ at $37^{\circ} \mathrm{C}$.

\section{Plasmid Construction and Establishment of the Gaussia Cell Line, Huh-7.5/EG(4A/4B)GLuc}

This method is provided in the Supporting Information S1 section.

\section{HCVcc Infections and Neutralizations}

JC1 virus was prepared as described [22] and used to inoculate Huh-7.5/EG(4A/4B)GLuc cells for $4 \mathrm{~h}$ previously seeded in 96 well plates, $1.2 \times 10^{4}$ cells/well. In the case of IFN$\alpha$ (Interferon- $\alpha \mathrm{A}$, Sigma-Aldrich, St. Louis, MO), $10 \mathrm{~h}$ postseeding, cells were washed $1 \mathrm{x}$ with PBS and fed with fresh DMEM complete supplemented with the indicated doses of IFN- $\alpha$ for $8 \mathrm{~h}$. In the case of anti-receptor inhibitions (antiCD81 mouse mAb clone JS-81, BD Pharmingen, San Diego, CA; or anti-SR-BI, clone C167, kindly provided by Dr. A. Nicosia), cells were treated with the indicated doses for $1 \mathrm{~h}$ prior to infection. Finally, viruses were incubated with the indicated amounts of anti-E2 human conformational mAb AR3A (kindly provided by Dr. M. Law) for $1 \mathrm{~h}$ at RT with gentle agitation prior to inoculation. Infections were performed always in duplicate wells measured in duplicates $(n=4)$. Results are given as percentage relative to control infections as follows: IFN- $\alpha$ relative to mock infections, anti-GD81 relative to mouse $\mathrm{IgG}_{1}$ isotype control (clone MOPC-31C, BD Pharmingen, San Diego, CA, anti-SR-BI and anti-E2 relative to human IgG (Southern Biotech, Birmingham, AL).

\section{Sera Collection and Inoculations}

Eighy-six patients who underwent liver transplantation due to HCV infection and who presented recurrent hepatitis posttransplantation were selected. Patient blood was collected in Vacutainer $^{\circledR}$ Rapid Serum Tube (Becton Dickinson, Franklin Lakes, NJ) and the serum was then separated after centrifugation at $1,000 \times \mathrm{g}$ for $10 \mathrm{~min}$. Serum was aliquoted and kept at $-80^{\circ} \mathrm{C}$. Viral load was determined by real-time PGR (COBAS TaqMan HCV Test, Roche Diagnostics, Mannheim, Germany). For inoculation of Huh-7.5/EG(4A/4B)GLuc cells, sera were thawed gently at $4^{\circ} \mathrm{C}$. DMEM complete was aspirated from cells, which were washed $3 \mathrm{x}$ with PBS. Sera were diluted 1:10, unless otherwise stated, to DMEM complete without FCS and the DMEM-sera mix was used to inoculate the cells, in duplicate. Four $\mathrm{h}$ postinoculation, DMEM-sera mix was aspirated, cells were washed $3 \mathrm{x}$ with PBS, and then fed with DMEM complete with FCS for $120 \mathrm{~h}$.

In vitro Transcription, Electroporation of HCV RNAs, Generation of HCVcc Stocks, and Determination of Virus Titers in cell Culture Supernatants

These methods were employed as previously described [22].

\section{Gaussia Luciferase Assay}

Gell culture supernatants from Huh-7.5/EG(4A/4B)GLuc cells were collected and centrifuged at $1,500 \times \mathrm{g}$ for $10 \mathrm{~min}$ and cell-free supernatants were kept at $4^{\circ} \mathrm{C}$ until Gaussia luciferase measurements were taken. For each well, $2 \times 50 \mu \mathrm{l}$ supernatant was mixed with $50 \mu \mathrm{l}$ Gaussia assay buffer (Gaussia Juice, PJK GmbH, Kleinblittersdorf, Germany) and then measured for $10 \mathrm{~s}$ in an Orion II Microplate Luminometer (Berthold Detection Systems, Pforzheim, Germany). 


\section{HCV RNA Quantification by RT-qPCR}

Viral RNA was isolated from HCVcc- or sera-inoculated cells and $25 \mathrm{ng}$ of the total RNA sample was used for RT-quantitative PCR analysis with 5' NTR-specific probe and primers as described in Supporting Information S1.

\section{Calculation of $\mathrm{S} / \mathrm{B}, \mathrm{S} / \mathrm{N}$, and Z-factor}

To validate the performance of the Huh-7.5/EG(4A/4B)GLuc cells for HTS assays, the signal-to-noise ratio $(\mathrm{S} / \mathrm{N})$, signal-tobackground $(\mathrm{S} / \mathrm{B})$ and $\mathrm{Z}$-factor values were calculated using the methods described by Zhang et. al. [23]. In JC1 replication inhibition, Huh-7.5/EG(4A/4B)GLuc cells were seeded in 96 well plates, $1.2 \times 10^{4}$ cells/well and treated with IFN- $\alpha(500 \mathrm{U} / \mathrm{ml})$ or mock-treated as described above, followed by infection with JC1 viruses at an MOI $0.5 \mathrm{TCID}_{50}$ /cell. In JC1 entry inhibition, cells were seeded as described above. $1 \mathrm{~h}$ prior to infection cells were treated with anti-CD81 or mouse monoclonal control antibodies (both at $1 \mu \mathrm{g} / \mathrm{ml}$ ). For each individual infection condition, 8 wells were used. At 5 days post infection, Gaussia activity was determined for each well in duplicate and $\mathrm{S} / \mathrm{B}, \mathrm{S} / \mathrm{N}$ and Z-factor values were calculated.

\section{Indirect Immunofluorescence}

$250 \mu \mathrm{l}$ of electroporated cells $\left(1 \times 10^{5}\right.$ cells $)$ were seeded on glass coverslips in 24-well plates. After $72 \mathrm{~h}$, cells were fixed with $4 \%$ paraformaldehyde in PBS and permeabilized with $0.5 \%$ Triton X-100 in PBS. In the case of patient sera or JC1 inoculations, cells were infected as described above, and fixed $96 \mathrm{~h}$ post inoculation. Immunostaining of NS5A protein was performed by using the mouse monoclonal 9E10 (kindly provided by Dr. C. Rice), of E2 protein by the anti-E2 human conformational mAb AR3A (kindly provided by Dr. M. Law) and of core by the mouse monoclonal anti-core antibody C7-50 (Santa Cruz Biotechnologies, Santa Cruz, CA), all at a final concentration of $1 \mu \mathrm{g} / \mathrm{ml}$ in PBS supplemented with $5 \%$ bovine serum albumin (BSA). Bound primary antibodies for the NS5A or the E2 were detected using goat $\alpha$-mouse antibodies conjugated to AlexaFluor ${ }^{\circledR} 568$ or goat $\alpha$-human antibodies conjugated to AlexaFluor ${ }^{\circledR} 488$ (Invitrogen, Eugene, OR), respectively, at a dilution of $1: 1,000$ in PBS with 5\% BSA. DNA was stained with DAPI (4', 6-Diamidino-2-phenylindole dihydrochloride) (Sigma-Aldrich, St. Louis, MO). Finally, cells were washed $3 \mathrm{x}$ with $\mathrm{PBS}$ and once with water and mounted on glass slides with Fluoromount G (Southern Biotechnology Associates, Birmingham, AL).

\section{Quantification of HCV Positive Cells}

To assess the number of HCV positive cells, cells seeded as described above were inoculated at various multiplicities of infection (MOI) for $4 \mathrm{~h}$. Five days post infection, cells were fixed and the proportion of infected cells was monitored by NS5Aspecific indirect immunofluorescence as described above. For each infection at least 1,000 cells were evaluated.

\section{Preparation of Cell Lysates, PAGE, and Western Blot Analysis}

In order to prepare cell lysates for Western blot analysis, cells were lysed with $1 \%$ Triton X-100 in PBS. Proteins present in the cell lysates were separated by SDS-PAGE electrophoresis and transferred to a PVDF membrane for claudin, occludin, NS3, core, GFP, $\beta$-actin or GAPDH detection. A detailed description of this method is provided in Supporting Information S1.

\section{Quantification of HCV Core Protein}

$\mathrm{HCV}$ core protein in cell culture supernatants was quantified using the Ortho ${ }^{\circledR} \mathrm{HCV}$ antigen ELISA test kit (Ortho Clinical Diagnostics, Tokyo, Japan). Cell culture supernatants were harvested $120 \mathrm{~h}$ post infection, filtered through $0.45-\mu \mathrm{m}$-pore-size filters and kept at $-80^{\circ} \mathrm{C}$ until the day of measurement. Colorimetric measurements were performed using a Sunrise colorimeter (Tecan Trading AG, Switzerland).

\section{Statistical Analyses}

Data are presented as mean \pm standard deviation (SD). The statistical comparison between two groups was made by a MannWhitney test. $p$ value $<0.05$ was considered to indicate a significant difference.

\section{Results}

Generation of the Huh-7.5/EG(4A/4B)GLuc Cell Line and Comparison with the Parental Huh-7.5 Cells

To generate a highly sensitive cell-based assay for $\mathrm{HCV}$ infectivity quantification, several reporter plasmids were constructed according to the NS3/4A-based reporter assay systems mentioned in the Introduction section. In our constructs the secreted alkaline phosphatase (SEAP) was replaced by the humanized form of the Gaussia luciferase (hGLuc) fused in-frame to the enhanced green fluorescence protein (EGFP) via various recognition sequences for the viral NS3/4A protease (Fig. 1A): i. the Cterminal region of IPS-1, encompassing the NS3/4A recognition site and a mitochondrial targeting sequence (amino acids 462-540, IPS $_{452-540)}$ ii. similar to (i) with the addition of an SV40 nuclear localization sequence (NLS) between the EGFP and the IPS segment (NLS-IPS ${ }_{462-540}$ ) iii. the ER retention signal (defined by amino acid sequence "KDEL") followed by octapeptide DEDEDEDE and the HCV genotype 1b NS4A/4B substrate sequence DEMEEC-ASHL iv. similar to (iii) without the ER retention signal.

Initially, these reporter constructs were transiently transfected to Huh-7.5 cells to examine whether they could be efficiently cleaved by NS3/4A protease following HCV infection (JC1 chimeric virus, at an MOI 0.5 TCID $_{50} /$ cell). At 5 days post infection, cell culture media were harvested and analyzed for Gaussia activity. As shown in Fig. 1B, elevated Gaussia levels, relative to control infections, were observed in these media harvested from cells that were transfected with the $\operatorname{EGFP}\left(\mathrm{DE}_{4 \mathrm{x}}-4 \mathrm{~A} / 4 \mathrm{~B}\right)$ GLuc construct. This construct was similar to that referred by Iro et. al. [18], although Pan et. al. [19], failed to detect elevated amounts of SEAP activity with the same construct in a transient transfection and infection assay. The lack of success with the other constructs, including the IPS constructs and the KDEL-DE ${ }_{4 \mathrm{x}}-4 \mathrm{~A} / 4 \mathrm{~B}$ cassette, suggests that the viral recognition sequence may not be accessible by the NS3/ $4 \mathrm{~A}$ protease caused by different protein conformations when the various peptide sequences are inserted into the chimera fusion protein.

Next, Huh-7.5 cells were stably transfected with plasmids encoding the $\operatorname{EGFP}\left(\mathrm{DE}_{4 \mathrm{x}}-4 \mathrm{~A} / 4 \mathrm{~B}\right)$ GLuc construct, selected for 4 weeks under the pressure of G418 antibiotic and finally sorted for high EGFP expression, thus generating the Huh-7.5/EG(4A/ 4B)GLuc cell line. Expression of the known HCV entry receptors CD81 [24], SR-BI [25], claudin [26] and occludin [27] in the Huh-7.5/EG(4A/4B)GLuc cell line proved equal to that of the parental Huh-7.5 cells (Fig. S1A-C). Similar entry profiles for both cells were confirmed with infections by HCVpp for various genotypes (Fig. S1D). HCV replication in the Huh-7.5/EG(4A/ 4B)GLuc cell line was assessed by: (i) electroporation of JFH-1 
B
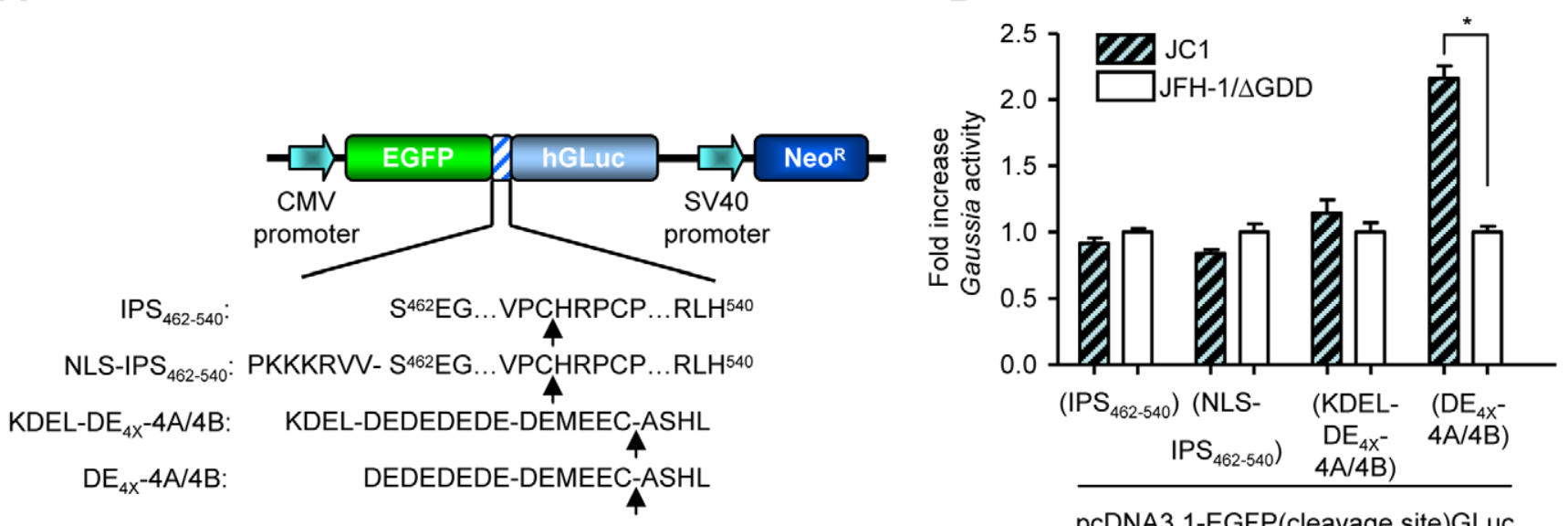

pcDNA3.1-EGFP(cleavage site)GLuc

Figure 1. Schematic of dual-function reporter vectors used in the HCV NS3/4A protease activity assay. (A) The various recognition sites

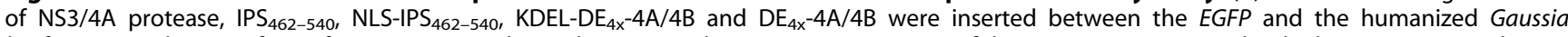
luciferase gene by an in-frame fusion. Arrows indicate the NS3/4A cleavage site. Expression of the reporter genes is under the human cytomegalovirus promoter (CMV) and the selection marker for the generation of the stable cell line is neomycin phosphotrasferase (Neo $)^{\mathrm{R}}$. SV40, simian virus 40 . (B) Transiently trasfected Huh-7.5 cells were infected with JC1 virus at an MOI 0.5 TCID $_{50}$ /cell or mock infected with JFH-1/ $\Delta$ GDD supernatant. At 5 days post infection, the medium was harvested and Gaussia activity was measured. Results are expressed as the mean values from duplicate wells, measured in duplicates, from a representative experiment of 3 (mean $\pm S D ; n=4)$. ${ }^{\prime}, P<0.05$.

doi:10.1371/journal.pone.0053254.g001

subgenomic replicons carrying the Firefly luciferase reporter (Fig. $\mathrm{S} 2 \mathrm{~A}$ ); and by (ii) electroporation of wild-type JFH-1 and the intraor inter-genotypic chimeric derivatives, JC1 and Conl/JFH-1, respectively [13] (Fig. S2B). Both methods demonstrated that HCV replicates to similar levels in both cell lines, as deduced by the degree of Firefly luciferase expression in the sub-genomic replicon assay and by the extent of NS5A and E2 expression in those cells transfected with full-length viruses.

\section{Determination of the Specificity of the Huh-7.5/EG(4A/ 4B)GLuc Cell-based System}

To assess the specificity of the Huh-7.5/EG(4A/4B)GLuc cell line, cells were infected with JC1 virus at an MOI 0.5 TCID $_{50}$ / cell, and Gaussia activity was determined at different time points. Concomitantly, cells were infected with supernatant from JFH-1/ $\Delta$ GDD-transfected cells as a negative control [22]. Gaussia activity acquired in JCl infected-cells was considered total (specific and unspecific) while that acquired in the negative control was regarded as unspecific. Specific signal (total minus unspecific) increased over the specified time course and reached levels up to 10-fold higher than the unspecific signal $120 \mathrm{~h}$ post-infection (Fig. 2A). To determine the sensitivity of the Huh-7.5/EG(4A/ 4B)GLuc cell line and the number of infected cells that produce Gaussia signal at a given viral concentration, cells were infected with JC1 viruses at various MOIs; 120 h post infection the Gaussia activity as well as the number of NS5A positive cells were measured. As shown in Fig. 2B and Fig. S3, the maximum specific signal reached a plateau when MOIs $\geq 0.5 \mathrm{TCID}_{50} /$ cell were administered, which was corresponded to $\geq 75 \%$ of positive cells. For each point in Fig. 2B, any unspecific signal by a $\Delta$ GDD infection $(\leq 10 \%)$ was subtracted.

\section{Correlation of Gaussia Activity with HCV RNA and Protein Levels \\ To demonstrate that the Gaussia activity secreted by the Huh- 7.5/EG(4A/4B)GLuc cells correlated with HCV RNA replication levels, the cell line was infected with JC1 or JFH-1 virus at an MOI}

$0.5 \mathrm{TCID}_{50}$ /cell. Subsequently, the Gaussia activity released in the medium and HCV RNA levels were determined side-by-side at different time points post-infection. As shown in Fig. 3A\&B, viral RNAs peaked around 72 or $96 \mathrm{~h}$ post-infection for the JC1 or the JFH-1 infection respectively, and declined thereafter due to cellular confluence. However, a time-dependent increase in Gaussia activity occurred as a result of increasing NS3/4A protease amounts and Gaussia stability. This result implies that the Gaussia levels do not directly correlate with virus RNA replication levels. Notably, although equal virus inocula were used for JC1 and JFH1 viruses, an approximately 2-fold higher RNA and Gaussia levels were detected in the JCl virus analysis in comparison to JFH-1. Both viruses posses the JFH-1 RNA replication machinery (proteins NS3-NS5B) and therefore differences in RNA levels cannot be explained by higher replication capacity of the JC1 chimeric virus. Previously it has been shown that JC1 and JFH-1 virus replicate to the same extent in Huh7 and Huh7-derived clones [13]. However, JCl virus produces a significantly higher amount of in vitro infectious virus at a more rapid kinetic manner and thus can spread faster in cell culture. Indeed, as shown in Fig. $\mathrm{S} 4$, at an MOI 0.1 $\mathrm{TCID}_{50}$ /cell, JC1 virus spread was faster than that of JFH-1.

To correlate Gaussia activity with viral protein expression, the viral intracellular protein (core and NS3) levels and the amount of EGFP still associated with Gaussia protein, were determined postinfection with the $\mathrm{JCl}$ virus at the same time points as previously. As shown in Fig. 3C, the cleavage induction between EG(4A/ 4B)GLuc correlated directly to increased NS3 protein levels. These data suggest that there needs to be a significant accumulation of NS3/4A post viral replication for efficient Gaussia cleavage and secretion which occurs at time points not earlier than $72 \mathrm{~h}$ post infection.

\section{Determination of Antiviral-mediated Neutralizations}

To determine the capability of the Huh-7.5/EG(4A/4B)GLuc cell line in antiviral-mediated neutralizations, cells were pretreated with replication or entry inhibitors (IFN- $\alpha$ or anti-receptor 
A

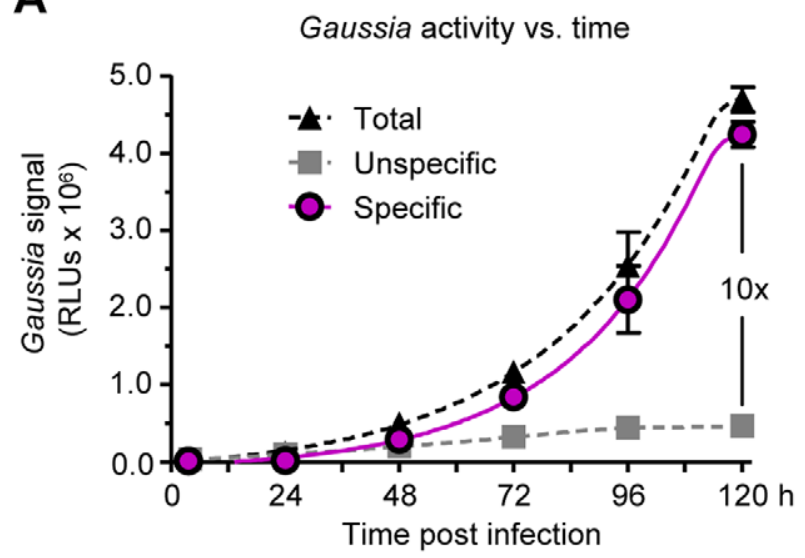

B

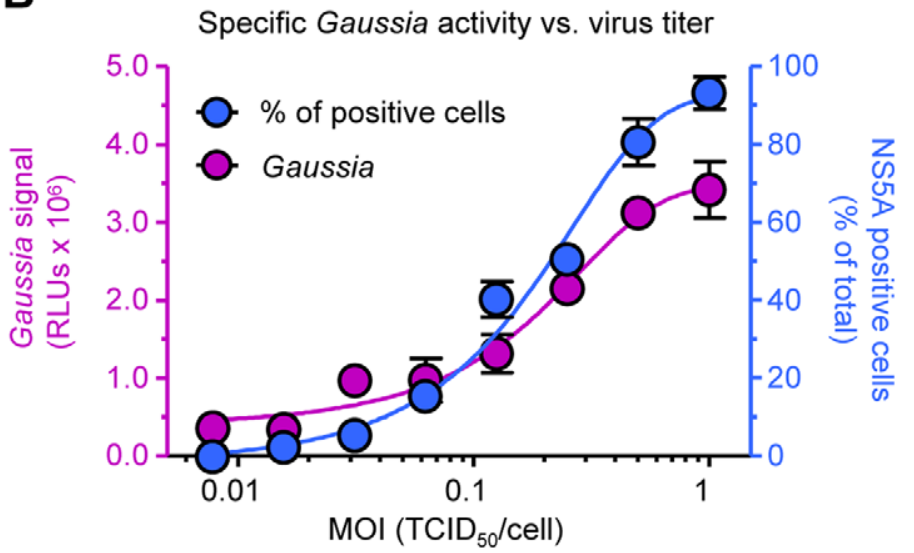

Figure 2. Specificity and sensitivity of the Huh-7.5/EG(4A/4B)GLuc reporter system. (A) Cells were infected with JC1 virus at an MOI of 0.5 $\mathrm{TCID}_{50}$ /cell or mock (JFH-1/ $\triangle \mathrm{GDD}$ ) infected. At the indicated time points, the Gaussia activity is given. (B) Cells were infected with JC1 virus at various MOIs $\left(1,0.5,0.25,0.125,0.0625,0.03125,0.015625,0.0 \mathrm{TCID}_{50} / \mathrm{ml}\right)$ and the specific (total minus unspecific) Gaussia activity for each infection condition is given 5 days post-infection. In parallel, the quantification of the fraction of infected cells was performed by using indirect immunofluorescence (NS5A positive cells). Results are expressed as the mean values from duplicate wells, measured in duplicates, from a representative experiment of 3 (mean $\pm \mathrm{SD} ; \mathrm{n}=4)$.

doi:10.1371/journal.pone.0053254.g002

antibodies [anti-CD81 or anti-SR-BI], respectively), or viruses were pre-incubated with the conformational anti-E2 antibody AR3A [28] prior to infection with JCl virus at an MOI of 0.5
TCID $_{50}$ /cell. A clear dose-dependent inhibition in Gaussia secretion was acquired for all inhibitors (Fig. 4A). Specifically, the half maximal inhibitory concentrations $\left(\mathrm{IC}_{50}\right)$ for the anti-
A

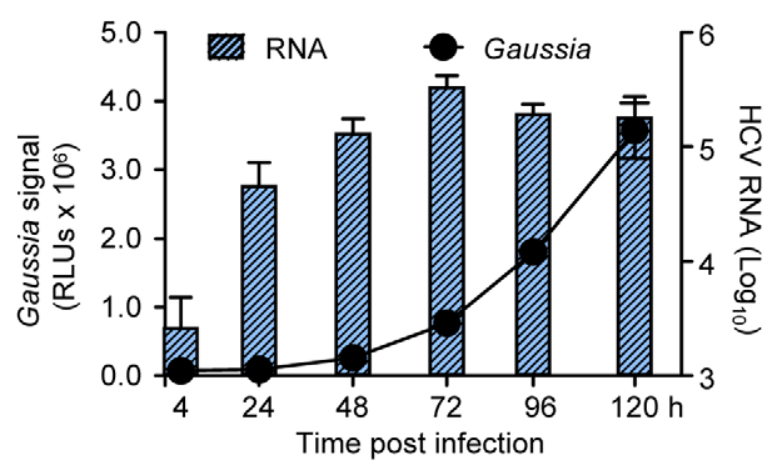

B

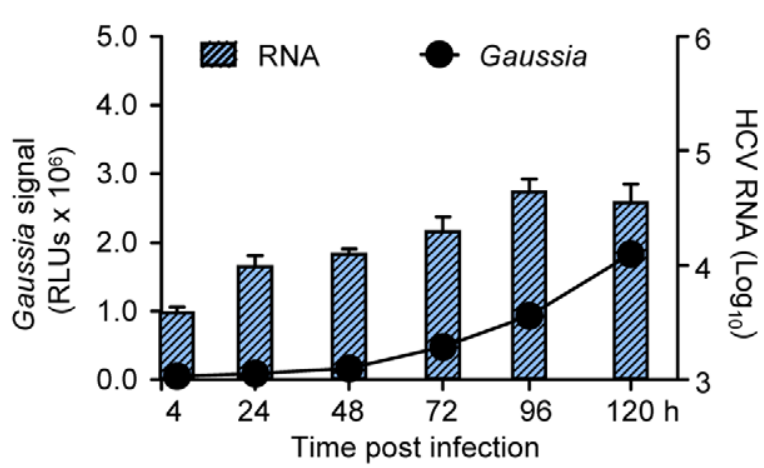

C Time post infection

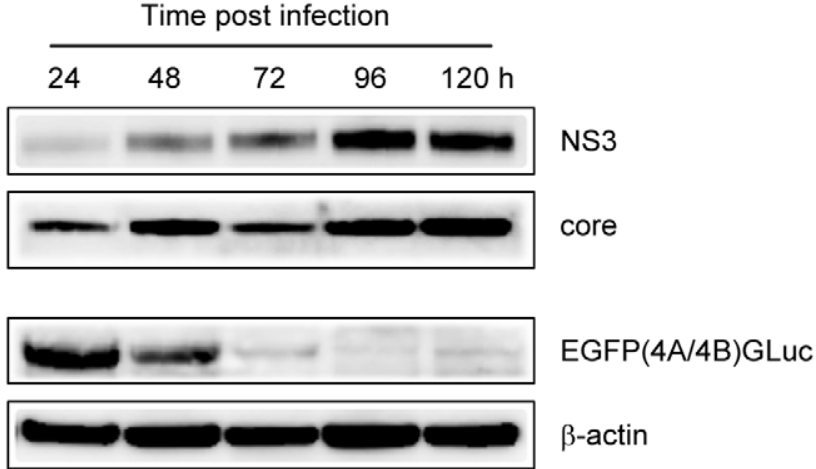

Figure 3. Correlation between extracellular Gaussia activity and HCV RNA and proteins. Huh-7.5/EG(4A/4B)GLuc cells were infected with $\mathrm{JC1}$ (A) or JFH-1 (B) viruses at an $\mathrm{MOI}$ of $0.5 \mathrm{TCID}_{50} /$ cell. Extracellular Gaussia activity and intracellular RNA were analyzed at the given time points post infection. (C) Correlation between NS3 and core proteins levels with EG(4A/4B)GLuc cleavage efficiency. Huh-7.5/EG(4A/4B)GLuc cells were infected like in (A) and at the given time points expression levels of NS3, core and EG(4A/4B)GLuc were analyzed by Western blotting by anti-NS3, anti-core and anti-GFP antibodies, respectively.

doi:10.1371/journal.pone.0053254.g003 
A

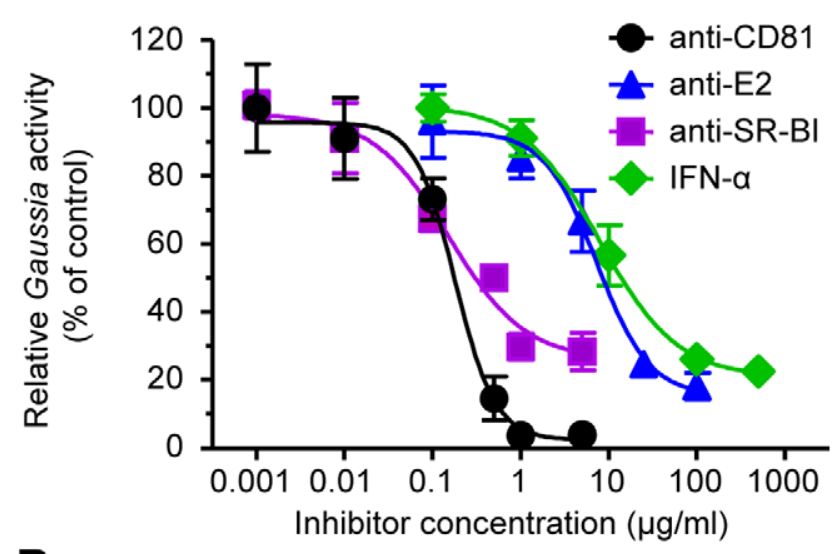

B
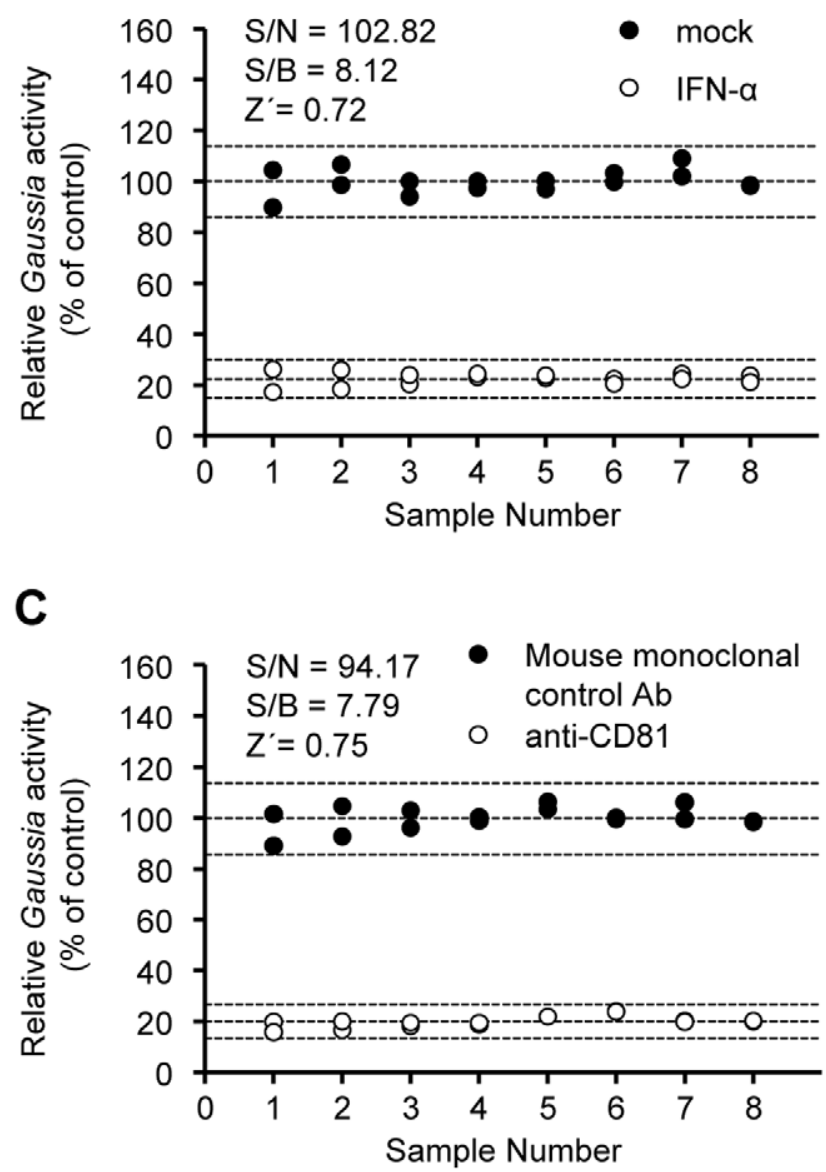

Figure 4. Quantification of HCVcc neutralization and estimates of statistical parameters of the screening system. (A) Huh-7.5/ $E G(4 A / 4 B) G L u c$ cells were pre-incubated with the indicated doses of IFN- $\alpha$, and anti-receptor antibodies (anti-CD81 or anti-SR-BI) or viruses were pre-incubated with anti-E2 antibodies prior to infections with JC1 virus (MOI $0.5 \mathrm{TCID}_{50}$ /cell). Gaussia specific activity was measured 5 days post-infection. The neutralizing activity is expressed as the percentage of inhibition, normalized to mock incubations. Results are from a representative experiment of three independent experiments. All points represent the mean of duplicate infections measured in duplicate (mean $\pm S D, n=4$ ). (B) Huh-7.5/EG $(4 A / 4 B$ ) GLuc cells were pretreated with IFN- $\alpha$ (open circles) or mock-treated (closed circles) for $18 \mathrm{~h}$ prior to infection with $\mathrm{JC} 1$ virus (MOI $0.5 \mathrm{TCID}_{50} /$ cell). 5 days post infection, Gaussia activity was measured and the statistical parameters $\mathrm{S} / \mathrm{N}, \mathrm{S} / \mathrm{B}$, and Z-factor were estimated. (C) Huh-7.5/EG(4A/4B)GLuc cells were infected in the presence of anti-CD81 (open circles) or mouse monoclonal control antibodies (closed circles). 5 days post infection $\mathrm{S} /$ $\mathrm{N}, \mathrm{S} / \mathrm{B}$, and Z-factor were estimated similar to (B). doi:10.1371/journal.pone.0053254.g004

CD81, anti-SR-BI, anti-E2 antibodies and IFN- $\alpha$ were $0.17,0.38$, 9.46 and $22.3 \mu \mathrm{g} / \mathrm{ml}$, respectively.

Next, we assessed whether the Huh-7.5/EG(4A/4B)GLuc cells can be adopted for a high-throughput screening (HTS) assay for novel anti-HCV agents. For this validation, we calculated the signal to noise ratio $(\mathrm{S} / \mathrm{N})$, signal to background ratio $(\mathrm{S} / \mathrm{B})$ and the Z-factor, in the presence or absence of IFN- $\alpha$ or anti-CD81 antibodies (replication or entry inhibitor, respectively), as described by Zhang et. al. [23]. As shown in Fig. 4B, the S/N and S/ $\mathrm{B}$ ratio and the $\mathrm{Z}$-factor for IFN- $\alpha$ were $102.82,8.12$ and 0.72 , respectively. Regarding the anti-GD81 antibodies (Fig. 4G), the S/ $\mathrm{N}, \mathrm{S} / \mathrm{B}$ ratio and the Z-factor were $94.17,7.79$ and 0.75, respectively.

Screening of HCV Positive Sera with the Capacity for in vitro Replication

We screened 86 sera derived from HCV genotype 1b-infected liver transplant recipients with respect to their in vitro replication potential by infecting the Huh-7.5/EG(4A/4B)GLuc cell line and deducing the Gaussia activity 5 d post-inoculation. The viral load in these samples ranged from $10^{6}$ to $10^{8} \mathrm{IU} / \mathrm{ml}$. To facilitate the Gaussia readout, we set a relative scale of reporter activity; specifically, Gaussia obtained from cells that were in parallel infected with JC1 viruses was set to 100 while that obtained from mock-infected cells (JFH-1/ $\mathrm{GDD}$ infections) and/or HCVnegative sera (HCV neg.) was set to 0 . Fig. 5A represents the results of three independent experiments while Fig. 5B represents the combined results of these experiments (means). Overall, Gaussia activity produced by cells infected with patient sera was low in comparison to that secreted by JC1 infected cells. Mean relative Gaussia activities for experiments 1, 2 and 3 were similar: $25.67 \pm$ $1.035,23.27 \pm 1.561$ and $24.80 \pm 1.491$, respectively $(\mathrm{p}=\mathrm{n} . \mathrm{s}$.). Additionally, although Gaussia activity acquired from cells infected by few patients in one experiment was significantly higher than the mean, this result was not reproducible in the next experiment. Hence, Table 1 summarizes those patients whose Gaussia activity post infection of Huh-7.5/EG(4A/4B)GLuc cells was $\geq 40 \%$ and reproducible in 3 experiments (patients also indicated in Fig. 5A). Worth noting is the fact that the in vitro infection and replication of serum-derived $\mathrm{HCV}$ in Huh-7.5/EG(4A/4B)GLuc cells did not correlate with the initial HCV serum-viral load; in fact, in vitro infectivities for high-HCV-containing sera $\left(10^{7}-10^{8} \mathrm{IU} / \mathrm{ml}\right.$, patient no. 67-86) were low.

To prove the specificity of serum infections, Huh-7.5/EG(4A/ 4B)GLuc cells were pre-incubated with anti-CD81 antibodies prior to inoculations with the selected sera presented in Table 1. As shown in Fig. 6A, JC1 control as well as serum infections were potently inhibited by anti-GD81 antibodies. To further corroborate this specificity, cells were inoculated with serial dilutions of JC1 viruses or sera and the Gaussia activity was monitored $120 \mathrm{~h}$ post infection (Fig. 6B). As expected, the magnitude of Gaussia activity correlated well with the amount of inoculum, demonstrating that it reflects the infectious titer in a quantitative manner.

To demonstrate that serum-derived HCV did replicate productively in Huh-7.5/EG(4A/4B)GLuc cells, HCV RNA and Gaussia activity were analyzed at different time points postinoculation for 2 patients. As shown in Fig. 7A\&B, both intracellular HCV RNA and extracellular Gaussia activity kinetics were similar to those obtained by HCVcc infections, indicating 
A

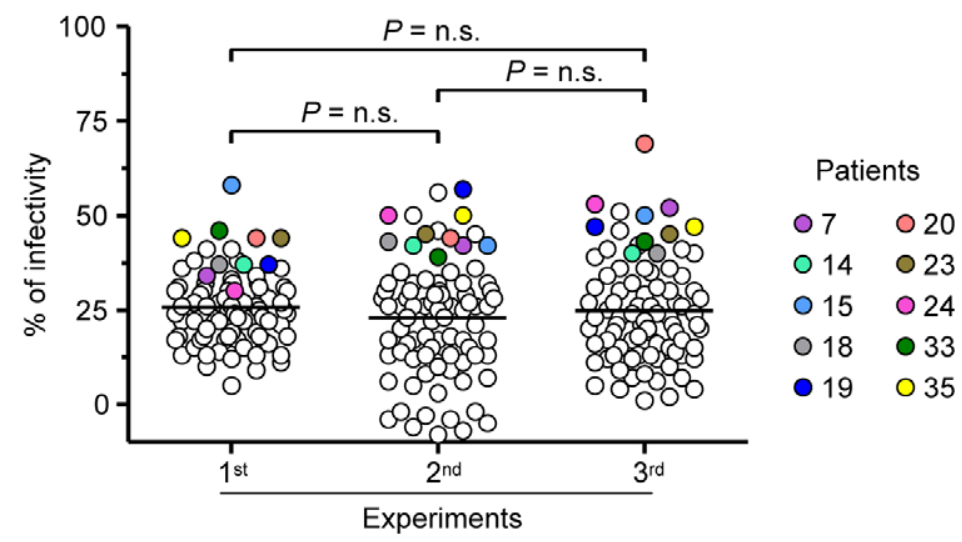

Patient Number

B

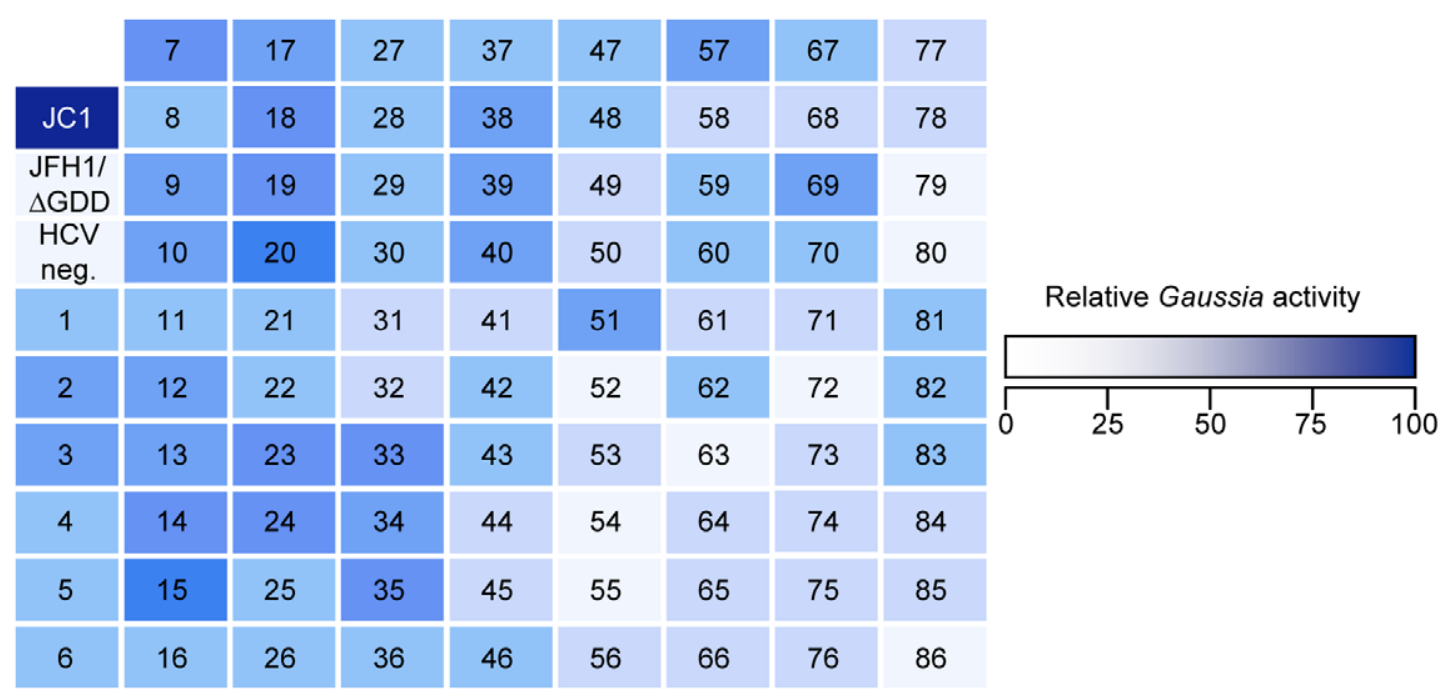

Figure 5. Overview of the screening strategy. (A) Eighty-six clinical sera were selected from patients as described in Materials and Methods. Patients number rise relative to the viral load increase. Relative Gaussia expression scale: Gaussia activity by wells infected in parallel with the JC1 virus at an $\mathrm{MOI}$ of $0.5 \mathrm{TCID}_{50}$ /cell was set at 100 while that by JFH-1/ $\triangle \mathrm{GDD}$ and/or HCV control negative serum (HCV neg.) was set at 0 . (A) Results from 3 representative experiments. Means difference between the experiments were not significant (n.s.). Patients with Gaussia activity $\geq 40 \%$ are indicated. (B) Colours were drawn according to the mean of 3 independent experiments. In each experiment duplicate infections were performed and measured in duplicate $(n=4)$.

doi:10.1371/journal.pone.0053254.g005

Table 1. List of patients with infectivity $\geq 40 \%$.

\begin{tabular}{lll}
\hline Patient Number & Viral Load $\left(\mathbf{I U} / \mathbf{m l} \times \mathbf{1 0}^{\mathbf{6}}\right)$ & Infectivity $^{\mathbf{a}}$ \\
\hline 7 & 2.58 & $42 \pm 10$ \\
14 & 3.40 & $40 \pm 3$ \\
15 & 3.41 & $50 \pm 8$ \\
18 & 3.82 & $40 \pm 3$ \\
19 & 3.93 & $47 \pm 10$ \\
20 & 4.14 & $52 \pm 14$ \\
23 & 4.33 & $44 \pm 1$ \\
24 & 4.45 & $46 \pm 9$ \\
33 & 5.00 & $43 \pm 4$ \\
35 & 5.00 & $47 \pm 3$ \\
\hline Infectivity is expressed as a percentage (\% \pm SD) relevant to that obtained \\
from cells infected in parallel with JC1 viruses. \\
doi:10.1371/journal.pone.0053254.t001
\end{tabular}

a productive in vitro replication of serum-derived HCV. Furthermore, immunofluorescence (IF) staining of capsid (core) protein in inoculated cells was performed (Fig. 7C). Core positive cells for JC1 infected cells were detectable as early as $24 \mathrm{~h}$ post infection whereas core positive cells for serum-inoculated cells were present from $72 \mathrm{~h}$ post inoculation and thereafter. IF staining $96 \mathrm{~h}$ post inoculation was substantially more intense in the JC1 infected cells. The less intense core signal in serum-inoculated rather reflects less RNA replication as deduced by the RT-qPCR data than antigenic differences by the anti-core antibody or distinct half-life times of the core molecules. Finally, extracellular core was measured by core ELISA $120 \mathrm{~h}$ post inoculation (Fig. 7D). Huh-7.5/EG(4A/ 4B)GLuc cells infected with JC1 viruses presented a significant core release $(\sim 500 \mathrm{fmol} / \mathrm{l})$. Interestingly, cells infected with patient sera did release measurable core amounts in the supernatant $(\sim 100 \mathrm{fmol} / \mathrm{l})$ suggesting that complete HCV replication took place in Huh-7.5/EG(4A/4B)GLuc cells post inoculation with the patient sera. 


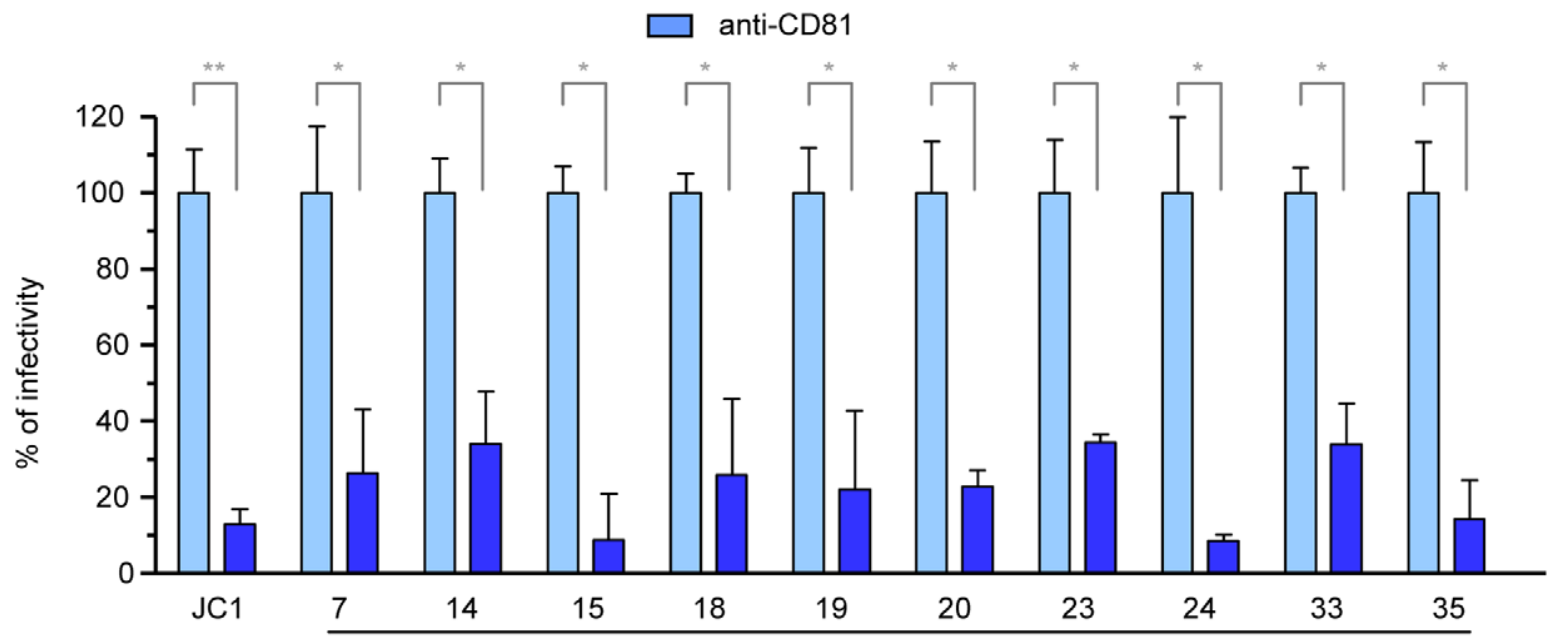

B

Patient Number

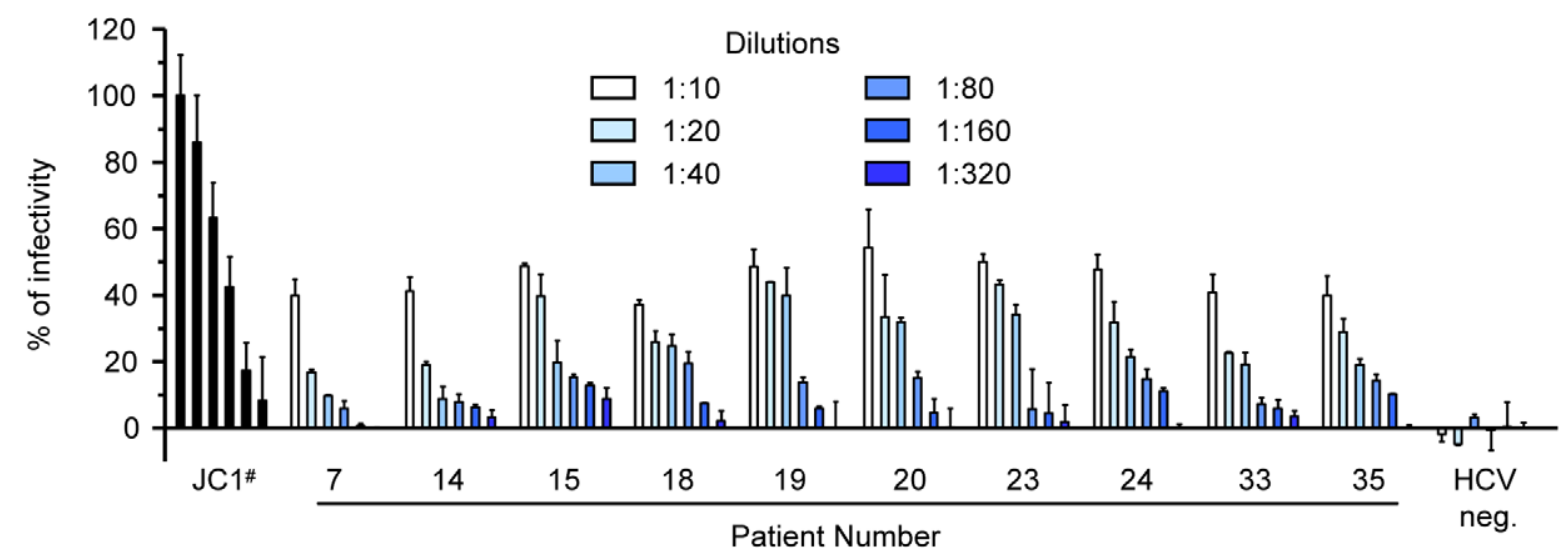

Figure 6. Specificity of serum infection by CD81-specific neutralizations and sera dilutions. (A) Huh-7.5/EG(4A/4B)GLuc cells were preincubated with CD81-specific (JS-81) antibodies or isotype-matched control antibodies for $1 \mathrm{~h}$ prior to infections. Gaussia activity in the anti-CD81 pre-incubated cells (dark blue bars) is expressed as percentage (\%) relative to that obtained for the control infections. Control infections are represented as light blue bars. (B) Huh-7.5/EG(4A/4B)GLuc cells were inoculated with serial dilutions of JC1 viruses, patient sera or control HCV negative serum. $120 \mathrm{~h}$ post infection Gaussia activity in the supernatant of the infected cells was determined. Results for (A) and (B) are expressed as the mean values from duplicate wells, measured in duplicates, from a representative experiment of 3 (mean $\pm S D ; n=4)$. \#Serial dilutions of JC1 virus: $\mathrm{MOI}$ at $1,0.5,0.25,0.125,0.0625$ and $0.03125 \mathrm{TCID}_{50} /$ cell.

doi:10.1371/journal.pone.0053254.g006

\section{Discussion}

In the present study we established a robust Gaussia luciferase cell line, designated Huh-7.5/EG(4A/4B)GLuc, which is as permissive as the parental Huh-7.5 cells in terms of $\mathrm{HCV}$ infection and in enabling the rapid and accurate quantification of $\mathrm{HCV}$ infections in cell culture via JFH-1 wild-type- or JFH-1derived viruses. We determined the secretion of Gaussia reporter activity based on the HCV NS3/4A protease activity, as has been previously described in other NS3/4A-dependent systems $[18,20,29]$.

Initially, several engineered Gaussia fusion proteins were constructed with diverse NS3/4A-cleavable peptides of NS3/4A protease. Out of the 4 constructs examined, only the $\operatorname{EGFP}\left(\mathrm{DE}_{4 \mathrm{x}^{-}}\right.$ 4A/4B)Gluc was functional (Fig. 1). Pan et. al., while developing their similar dual reporter cell line Huh-7.5/EG( $\Delta 4 \mathrm{~B} 5 \mathrm{~A}) \mathrm{SEAP}$ [19], checked various cleavable peptides as well, including the 4A/ 4B signal sequence utilized in this study. In an EGFP-SEAP configuration, the $4 \mathrm{~A} / 4 \mathrm{~B}$ cleavage site appeared to be inaccessible by the viral protease. Indeed, Iro $e t$. al. [18], demonstrated that the insertion of the octapeptide DEDEDEDE prior to the NS4A/4B recognition sequence is crucial for a cleavage efficiency enhancement, which appeared also true for our EGFP-Gaussia configuration. Interestingly, we established Huh-7.5/EGFP-IPS and Huh7.5/EGFP-NLS-IPS cells lines, similar to Jones et. al. [20]; in these cells, upon JC1 infection, we observed EGFP re-localization in the whole cytoplasm or in the nucleus, respectively (data not shown). Nonetheless, C-terminal Gaussia gene addition to both EGFP-IPS chimeric configurations appeared ineffective with respect to specific Gaussia secretion upon JC1 infection, likely due to cleavage interference caused by different protein conformations.

Our Gaussia-based reporter system appears a better alternative than the previously reported SEAP cell lines. Indeed, the Huh7.5/EG(4A/4B)GLuc cell line combines the advantages of the previously reported Huh7-J20 and Huh-7.5/EG(A4B5A)SEAP cell lines while also retaining the unique features of the Gaussia 
A

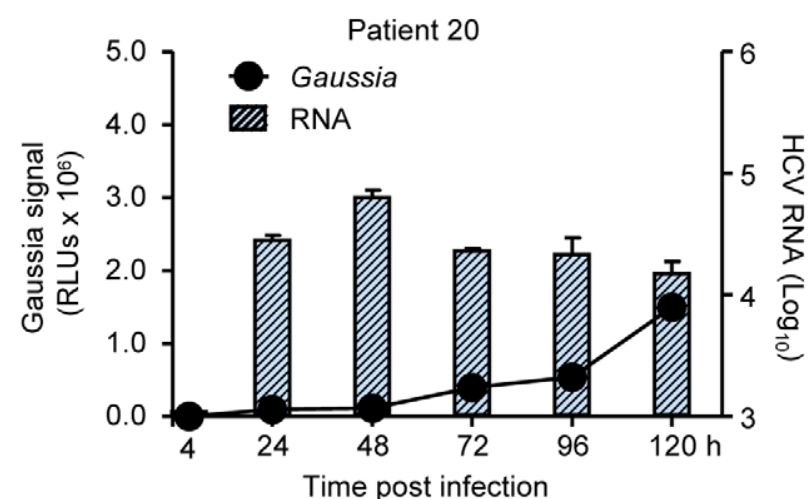

C

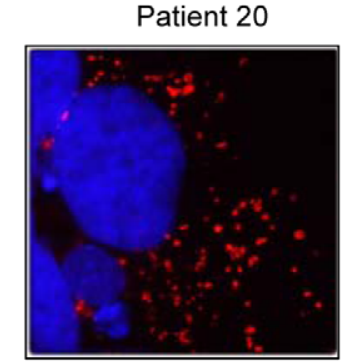

JC1

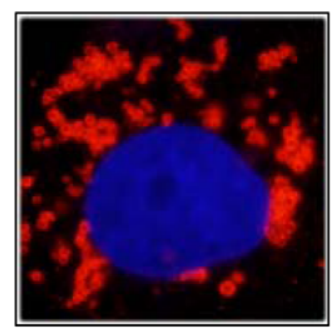

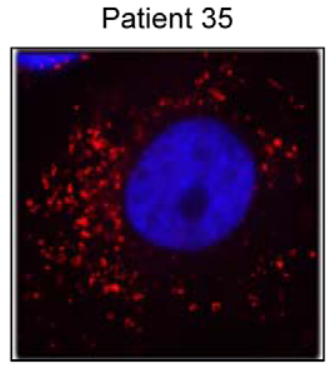

HCV neg. serum

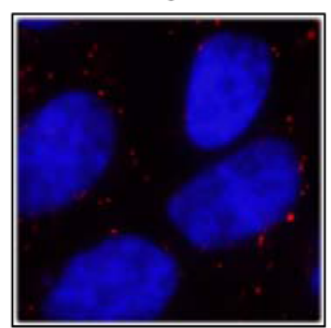

B

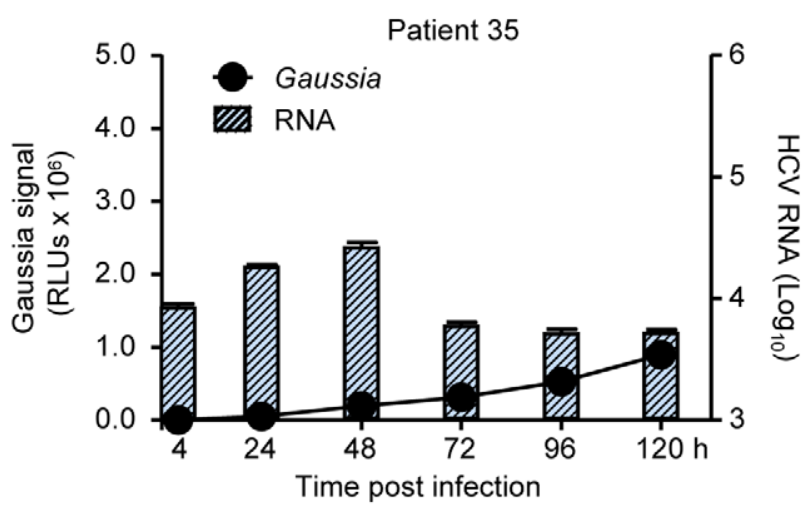

D

Figure 7. Productive replication of serum-derived HCV in Huh-7.5/EG(4A/4B)GLuc cells. (A\&B) Gaussia activity and intracellular HCV RNA analysis in Huh-7.5/EG(4A/4B)GLuc cells inoculated with sera derived from patients 20 and 35 at the indicated time points. Results represent the mean values from duplicate wells, measured in duplicate (for both Gaussia and RNA), from a representative experiment of 3 (mean \pm SD; $n=4)$ (C) Intracellular core expression in Huh-7.5/EG(4A/4B)GLuc cells inoculated with the indicated patient sera, JC1 virus or HCV negative Serum (HCV neg.) as negative control, as detected by core protein IF. Cells were stained with $\alpha$-core specific antibodies (clone C7-50) and $\alpha$-mouse Alexa-568 antibodies (red). Cell nuclei were counterstained with DAPI (blue), magnification 100x. (D) Core protein released in the supernatant from Huh-7.5/ $\mathrm{EG}(4 \mathrm{~A} / 4 \mathrm{~B}) \mathrm{GLuc}$ cells infected by the indicated patient sera, JC1 virus or HCV neg. serum as negative control, $120 \mathrm{~h}$ post inoculation. doi:10.1371/journal.pone.0053254.g007

reporter. These specialized features can be enumerated: (i) as Gaussia is naturally secreted into the media, no cell lysis is required for the detection of its enzymatic activity; (ii) the secreted indicator function not only permits multiple kinetics experiments using only one culture through the sequential sampling of the medium, but also allows the cells to be used for other purposes, such as RNA extraction, Western blot analysis, and other assays; (iii) Gaussia is non-toxic and very potent - compared to the humanized forms of firefly (hFLuc) and Renilla (hRLuc) luciferases expressed under similar conditions, the humanized form of Gaussia (hGLuc) generates over a 1000-fold higher bioluminescent signal intensity from live cells (in concert with their immediate environment) and over a 100-fold higher intensity from viable cells alone (not including secreted luciferase) or cell lysates [21]; (iv) Gaussia is stable in culture medium (with a half-life $\sim 6$ d) [30] and samples can thus be stored at $4^{\circ} \mathrm{C}$ for several days without any significant change in its activity levels; (v) it is HCV genotype-independent, and therefore does not require any genetic modification of the viral genomes, due to the highly conserved nature of the NS3/4A recognition sequence [31].

Characterization of the Huh-7.5/EG(4A/4B)GLuc cell line demonstrated that Gaussia activity in the culture medium correlated precisely with the virus inoculum (Fig. 2B). In order to obtain maximum Gaussia sensitivity, however, virus inoculations should be performed with $\mathrm{MOI} \geq 0.5 \mathrm{TCID}_{50} /$ cell, although accurate infection quantifications were possible with MOIs as low as $\leq 0.1 \mathrm{TCID}_{50} / \mathrm{ml}$. This unique characteristic suggests that the Huh-7.5/EG(4A/4B)GLuc reporter system could be utilized in studies where small or slowly replicating virus samples could applied; e.g., in the screening of patient sera for the presence of in vitro replication-competent isolates. In addition, we also showed that a 5-day infection assay is the optimal time condition for achieving significant increased amounts of Gaussia activity in culture medium (Fig. 2A) although already at day 4 post-infection Gaussia activity was detectable. This time-frame brings our assay at the same position like that presented by Iro et. al., and 1 day faster than that presented by Pan et. al. In contrast, Jones et. al., were able 
to monitor $\mathrm{HCV}$ infection by fluorescence re-localization in their Huh-7.5 cells expressing RFP-NLS-IPS construct as early as 10$12 \mathrm{~h}$ post infection. This fluorescence system appeals ideal for live cell microscopy at a single-cell level, which makes it attractive for elucidation of viral and cellular mechanisms during HCV life cycle. Whether that system could be applied for HTS assays needs to be addressed; microscopy-based HTS have been already described, though with the demand of costly microscopy apparatus and computer software.

Gaussia read from Huh-7.5/EG(4A/4B)GLuc cells infected in the presence of selected inhibitors (IFN- $\alpha$ or entry inhibitors) demonstrated the potential use of this reporter system for HTS of entry inhibitors and other antiviral compounds. Estimates of statistical parameters for a potential screening system exist only in the study of Pan et. al. In our system, the $\mathrm{S} / \mathrm{N}, \mathrm{S} / \mathrm{B}$ ratio and the Z-factor ranged between 94.17-102.82, 7.79-8.12 and 0.72-0.75, respectively, clearly superior to the SEAP reporter cell line whose these parameters ranged between $21.2-34-1,3.8-3.9$ and 0.64 0.74 , respectively.

Since the discovery of HCV in 1989, several researchers have tried to inoculate cells in vitro using serum-derived HCV. These efforts involved liver cells as well as cells of non-liver origin including HeLa, CEM, H9, Jurkat, Molt 3, Molt 4, U937, P3HR1, Raji and Daudi cells [32]. Although the JFH-1 isolate can replicate in hepatoma cell lines of human and murine origin [33], high replication levels can only be achieved in select subclones of the human hepatoma cell line Huh-7, which are highly permissive for HCV replication; e.g., Huh-7.5 [9] or Lunet cells [10]. These cell lines harboured a subgenomic replicon and were "cured" by IFN- $\alpha$ or a polymerase inhibitor, thereby preserving the high replication capacity observed in HCV.

In this study, we provide evidence for a productive infection and replication of the Huh-7.5/EG(4A/4B)GLuc cells by clinical sera derived by patients who underwent liver transplantation due to $\mathrm{HCV}$ infection and who presented recurrent hepatitis posttransplantation. Studies on HCV kinetics during and immediately after LT have shown that, although a rapid drop of HCV viral load occurs within the initial hours after liver graft reperfusion, the viral load increases as soon as $12 \mathrm{~h}$ after graft reperfusion exceeding pre-transplantation levels by 1 to 3 months after transplantation in a significant portion of HCV patients who undergo liver transplantation [34]. Here, we chose eighty-six sera harvested 3-6 months post LT from patients with hepatitis C recurrence. In the transplant setting however, the anti-HCV response takes place (in most cases) in the context of a nonself histocompatibility complex, in addition to strong immunosupression [35]. Additionally, viral load values in transplant patients exceed pre-LT values by $0.96 \mathrm{log} \mathrm{IU} / \mathrm{ml}$ [36]. These data argue for a LT patient-sera selection against sera derived by chronic patients. Indeed, $\sim 12 \%$ of those LT-patient sera contained in vitro replication-competent viruses, as deduced by the Gaussia signal, real time quantitative PCR, immunofluorescence and capsid protein secretion. Nevertheless, this infection was less efficient than that with recombinant $\mathrm{HCV}$ virus produced in cell culture.

Since the initial discovery of the JFH-1 virus and its extraordinary capacity to support the complete HCV life cycle in vitro several JFH-1-derived chimeric virus with other isolates have been described [12,13,14,37,38]. Common characteristic of these chimeric viruses (except the chimeric virus JC1) is the requirement of cell culture adaptive mutations that increase virus titers without affecting replication. This finding was also true for the initial JFH-1 genome [39,40]. Our RNA and Gaussia kinetic analyses for JC1, JFH-1 and sera-inoculated cells (Fig. 2 and 6) suggest that although natural viruses contained in patient sera were able to infect Huh-7.5/EG(4A/4B)GLuc cells and propagate in vitro, their replication and spread kinetics are less efficient than those obtained with the highly in vitro adapted JC1 virus. Seraderived HCV appears a weakness rather for in vitro replication than entry into Huh-7.5 cells (G. Koutsoudakis and X. Forns, unpublished data) which may cause the major contribution for the in vitro propagation incompetence. However, our results presented in Fig. $6 \& 7$ clearly show a productive infection of Huh-7.5/ EG(4A/4B)GLuc cells by patient sera.

Furthermore, although our extensive efforts to minimize interassay variation which could have been produced by manipulations of the sera (e.g. multiple freeze-and-thaw cycles) or the Gaussia assay itself (e.g. maintain the same source of Gaussia substrate), the results obtained by a single serum infection may vary at a higher level in comparison to JC1 infections. Indeed, JCl virus is the product of a unique clone and it was always prepared fresh; clinical sera contain a variety of infectious and non-infectious quasispecies which could produce some extra variation among experiments. Therefore, in order to confirm our infection results produced by the initial screening (Fig. 5), in the subsequent experiments (Fig. $6 \& 7$ ) we chose only those sera with the highest infection capacity accompanied by high inter-assay reproducibility. Our efforts at the moment concentrate on testing the infectious progeny release in infection experiments or whether these patientderived viruses could establish persistent infection in cell culture. Assuming that we could be successful in these efforts, we do believe that we should proceed in cloning new recombinant HCV isolates which may also posses cell culture adaptive mutations.

Altogether, we believe that our robust, specific, and sensitive Gaussia cell-based assay, utilizing the Huh-7.5/EG(4A/4B)GLuc cell line, will facilitate the further screening of in vitro replicationcompetent serum-derived viruses, as well as the subsequent cloning of recombinant $\mathrm{HCV}$ isolates. In addition, we believe it will prove effective for the HTS of entry inhibitors and other antiviral compounds.

\section{Supporting Information}

Figure S1 HCV receptor and HCVpp entry analyses in Huh-7.5 and Huh-7.5/EG(4A/4B)GLuc cells. (A \& B) Expression of SR-BI and CD81 on the surfaces of Huh-7.5 or Huh-7.5/EG(4A/4B)GLuc cells, respectively. (C) Occludin and claudin expression as determined by Western blot. (D) Infectivity of Huh-7.5 vs. Huh-7.5/EG(4A/4B)GLuc cells with HCVpp. Results are expressed as the mean values from duplicate wells, measured in duplicates from a representative experiment of 3 (mean $\pm \mathrm{SD} ; \mathrm{n}=4)$.

(TIF)

Figure S2 HCV replication analysis in Huh-7.5 and Huh-7.5/EG(4A/4B)GLuc cells. (A) Firefly luciferase activity in Huh-7.5 vs. Huh-7.5/EG(4A/4B)GLuc electroporated cells with the subgenomic replicon RNAs carrying Firefly luciferase as a reporter. Results are expressed as the mean values from duplicate wells, measured in triplicate, from a representative experiment of 3 (mean $\pm \mathrm{SD} ; \mathrm{n}=6$ ). (B) Immunofluorescence analysis of Huh-7.5/EG(4A/4B)GLuc cells electroporated with JC1 (panels $I$ to $I V$ ), Conl/JFH-1 (panels $V$ to VIII), or JFH-1 (panels $I X$ to $X I I$ ) or Huh-7.5 cells electroporated with JC1 (panels $X I I I$ to $X I V$, positive control). Cells were stained with anti-E2 specific antibodies or anti-NS5A specific antibodies and antihuman Alexa-468 (green) or anti-mouse Alexa-568 (red) antibodies, respectively. Cell nuclei were counterstained with DAPI (blue), magnification 100x.

(TIF) 
Figure S3 Immunofluorescence analysis of Huh-7.5/ EG $(4 A / 4 B) G L u c$ cells 120 h post infection with JC1 virus. Huh-7.5/EG(4A/4B)GLuc cells were infected with JC1 virus at various MOIs as indicated on each image. Cells were stained with anti-NS5A specific antibodies and anti-mouse Alexa568 (red) antibodies. Cell nuclei were counterstained with DAPI (blue), magnification 20x.

(TIF)

Figure S4 Immunofluorescence analysis of Huh-7.5/ EG $(4 \mathrm{~A} / 4 \mathrm{~B})$ GLuc cells infected with JG1 or JFH-1 viruses at an MOI 0.1 TCID $_{50} /$ cell. Cells were infected with JC1 or $\mathrm{JFH}-1$ viruses and at the indicated time points post infection cells were stained with anti-NS5A specific antibodies and anti-mouse Alexa-568 (red) antibodies. Cell nuclei were counterstained with DAPI (blue), magnification 10x.

(TIF)

Supporting Information S1 Protocols for plasmid construction and establishment of the Gaussia cell line Huh7.5/EG(4A/4B)GLuc, HCVpp production and infection, flow cytometry, transient HCV replication using Firefly

\section{References}

1. Shepard CW, Finelli L, Alter MJ (2005) Global epidemiology of hepatitis C virus infection. Lancet Infect Dis 5: 558-567.

2. Simmonds P, Bukh J, Combet C, Deleage G, Enomoto N, et al. (2005) Consensus proposals for a unified system of nomenclature of hepatitis $\mathrm{C}$ virus genotypes. Hepatology 42: 962-973.

3. Moradpour D, Penin F, Rice CM (2007) Replication of hepatitis C virus. Nat Rev Microbiol 5: 453-463.

4. Simmonds P (1995) Variability of hepatitis C virus. Hepatology 21: 570-583.

5. Cornberg M, Razavi HA, Alberti A, Bernasconi E, Buti M, et al. (2011) A systematic review of hepatitis $\mathrm{C}$ virus epidemiology in Europe, Canada and Israel. Liver Int 31 Suppl 2: 30-60.

6. Lohmann V, Korner F, Koch J, Herian U, Theilmann L, et al. (1999) Replication of subgenomic hepatitis C virus RNAs in a hepatoma cell line. Science 285: 110-113.

7. Blight KJ, Kolykhalov AA, Rice CM (2000) Efficient initiation of HCV RNA replication in cell culture. Science 290: 1972-1974.

8. Blight KJ, McKeating JA, Marcotrigiano J, Rice CM (2003) Efficient replication of hepatitis C virus genotype 1a RNAs in cell culture. J Virol 77: 3181-3190.

9. Blight KJ, McKeating JA, Rice CM (2002) Highly permissive cell lines for subgenomic and genomic hepatitis C virus RNA replication. J Virol 76: 1300113014.

10. Friebe P, Boudet J, Simorre JP, Bartenschlager R (2005) Kissing-loop interaction in the $3^{\prime}$ end of the hepatitis $\mathrm{C}$ virus genome essential for RNA replication. J Virol 79: 380-392.

11. Wakita T, Pietschmann T, Kato T, Date T, Miyamoto M, et al. (2005) Production of infectious hepatitis $\mathrm{C}$ virus in tissue culture from a cloned viral genome. Nat Med 11: 791-796.

12. Lindenbach BD, Evans MJ, Syder AJ, Wolk B, Tellinghuisen TL, et al. (2005) Complete replication of hepatitis C virus in cell culture. Science 309: 623-626.

13. Pietschmann T, Kaul A, Koutsoudakis G, Shavinskaya A, Kallis S, et al. (2006) Construction and characterization of infectious intragenotypic and intergenotypic hepatitis G virus chimeras. Proc Natl Acad Sci U S A 103: 7408-7413.

14. Gottwein JM, Scheel TK, Jensen TB, Lademann JB, Prentoe JC, et al. (2009) Development and characterization of hepatitis $\mathrm{C}$ virus genotype $1-7$ cell culture systems: role of CD81 and scavenger receptor class B type I and effect of antiviral drugs. Hepatology 49: 364-377.

15. Koutsoudakis G, Kaul A, Steinmann E, Kallis S, Lohmann V, et al. (2006) Characterization of the early steps of hepatitis $\mathrm{C}$ virus infection by using luciferase reporter viruses. J Virol 80: 5308-5320.

16. Schaller T, Appel N, Koutsoudakis G, Kallis S, Lohmann V, et al. (2007) Analysis of hepatitis $\mathrm{C}$ virus superinfection exclusion by using novel fluorochrome gene-tagged viral genomes. J Virol 81: 4591-4603.

17. Lee JC, Yu MC, Lien TW, Chang GF, Hsu JT (2005) High-throughput cellbased screening for hepatitis $\mathrm{C}$ virus NS3/4A protease inhibitors. Assay Drug Dev Technol 3: 385-392.

18. Iro M, Witteveldt J, Angus AG, Woerz I, Kaul A, et al. (2009) A reporter cell line for rapid and sensitive evaluation of hepatitis $\mathrm{C}$ virus infectivity and replication. Antiviral Res 83: 148-155.

19. Pan KL, Lee JC, Sung HW, Chang TY, Hsu JT (2009) Development of NS3/ $4 \mathrm{~A}$ protease-based reporter assay suitable for efficiently assessing hepatitis $\mathrm{C}$ virus infection. Antimicrob Agents Chemother 53: 4825-4834. luciferase reporter genomes, HCV RNA quantification by RT-qPGR and preparation of cell lysates, PAGE, and Western blot analysis are provided in this section. (DOC)

\section{Acknowledgments}

The authors are grateful to Dr. Miguel Angel Martinez (Institut de Recerca de la SIDA irsiCaixa, Hospital Universitari Germans Trias I Pujol, Badalona, Spain) for the cooperation and the usage of the P3 facilities. Authors would like also to acknowledge Dr. Charles Rice (The Rockefeller University, New York, USA) for providing the Huh-7.5 cells, Prof. Ralf Bartenschlager (Department of Molecular Virology, University of Heidelberg, Germany) for the luciferase-carrying JFH-1 viruses, Dr. Alfredo Nicosia (Okairós A.G., Naples, Italy) for providing the anti-SR-BI G167 antibody and Dr. M Law (The Scripps Research Institute, La Jolla, USA) for the AR3A anti-E2 antibody.

\section{Author Contributions}

Conceived and designed the experiments: GK XF. Performed the experiments: GK SPP PG GG. Analyzed the data: GK SPP MN XF. Wrote the paper: GK SPP XF.

20. Jones CT, Catanese MT, Law LM, Khetani SR, Syder AJ, et al. (2010) Realtime imaging of hepatitis $\mathrm{C}$ virus infection using a fluorescent cell-based reporter system. Nat Biotechnol 28: 167-171.

21. Tannous BA, Kim DE, Fernandez JL, Weissleder R, Breakefield XO (2005) Codon-optimized Gaussia luciferase cDNA for mammalian gene expression in culture and in vivo. Mol Ther 11: 435-443.

22. Koutsoudakis G, Perez-Del-Pulgar S, Coto-Llerena M, Gonzalez P, Dragun J, et al. (2011) Cell culture replication of a genotype $1 \mathrm{~b}$ hepatitis $\mathrm{C}$ virus isolate cloned from a patient who underwent liver transplantation. PLoS One 6: e23587.

23. Zhang JH, Chung TD, Oldenburg KR (1999) A Simple Statistical Parameter for Use in Evaluation and Validation of High Throughput Screening Assays. J Biomol Screen 4: 67-73.

24. Pileri P, Uematsu Y, Campagnoli S, Galli G, Falugi F, et al. (1998) Binding of hepatitis $\mathrm{C}$ virus to CD81. Science 282: 938-941.

25. Scarselli E, Ansuini H, Cerino R, Roccasecca RM, Acali S, et al. (2002) The human scavenger receptor class $\mathrm{B}$ type $\mathrm{I}$ is a novel candidate receptor for the hepatitis $\mathrm{C}$ virus. EMBO J 21: 5017-5025.

26. Evans MJ, von Hahn T, Tscherne DM, Syder AJ, Panis M, et al. (2007) Claudin-1 is a hepatitis $\mathrm{C}$ virus co-receptor required for a late step in entry. Nature 446: 801-805.

27. Ploss A, Evans MJ, Gaysinskaya VA, Panis M, You H, et al. (2009) Human occludin is a hepatitis $\mathrm{C}$ virus entry factor required for infection of mouse cells. Nature 457: 882-886.

28. Law M, Maruyama T, Lewis J, Giang E, Tarr AW, et al. (2008) Broadly neutralizing antibodies protect against hepatitis $\mathrm{C}$ virus quasispecies challenge. Nat Med 14: 25-27.

29. Lee JW, Jung M, Rosania GR, Chang YT (2003) Development of novel cellpermeable DNA sensitive dyes using combinatorial synthesis and cell-based screening. Chem Commun (Camb): 1852-1853.

30. Wurdinger T, Badr C, Pike L, de Kleine R, Weissleder R, et al. (2008) A secreted luciferase for ex vivo monitoring of in vivo processes. Nat Methods 5: $171-173$.

31. Grakoui A, McCourt DW, Wychowski C, Feinstone SM, Rice CM (1993) Characterization of the hepatitis $\mathrm{C}$ virus-encoded serine proteinase: determination of proteinase-dependent polyprotein cleavage sites. J Virol 67: 2832-2843.

32. Kato N, Shimotohno K (2000) Systems to culture hepatitis G virus. Curr Top Microbiol Immunol 242: 261-278.

33. Long G, Hiet MS, Windisch MP, Lee JY, Lohmann V, et al (2011) Mouse hepatic cells support assembly of infectious hepatitis $\mathrm{C}$ virus particles. Gastroenterology 141: 1057-1066.

34. Garcia-Retortillo M, Forns X, Feliu A, Moitinho E, Costa J, et al. (2002) Hepatitis $\mathrm{C}$ virus kinetics during and immediately after liver transplantation. Hepatology 35: 680-687

35. Rosen HR (2008) Transplantation immunology: what the clinician needs to know for immunotherapy. Gastroenterology 134: 1789-1801.

36. Dragun J, Perez-Del-Pulgar S, Crespo G, Ramirez S, Coto-Llerena M, et al. (2011) Characterization of the cross-neutralizing antibody response against hepatitis $\mathrm{C}$ virus in the liver transplantation setting. Am J Transplant 11: 767774 .

37. Gottwein JM, Scheel TK, Hoegh AM, Lademann JB, Eugen-Olsen J, et al. (2007) Robust hepatitis C genotype 3a cell culture releasing adapted intergenotypic 3a/2a (S52/JFH1) viruses. Gastroenterology 133: 1614-1626. 
38. Scheel TK, Gottwein JM, Jensen TB, Prentoe JC, Hoegh AM, et al. (2008) Development of JFH1-based cell culture systems for hepatitis C virus genotype 4a and evidence for cross-genotype neutralization. Proc Natl Acad Sci U S A 105: 997-1002.
39. Kaul A, Woerz I, Meuleman P, Leroux-Roels G, Bartenschlager R (2007) Cell culture adaptation of hepatitis $\mathrm{C}$ virus and in vivo viability of an adapted variant. J Virol 81: 13168-13179.

40. Zhong J, Gastaminza P, Chung J, Stamataki Z, Isogawa M, et al. (2006) Persistent hepatitis $\mathrm{C}$ virus infection in vitro: coevolution of virus and host. J Virol 80: 11082-11093. 